\title{
URGENSI SUPERVISI PENDIDIKAN DI SEKOLAH
}

\author{
M. Bustanul Ulum \\ Dosen IAI Al Falah As Sunniyyah Kencong Jember \\ email: bustanululum@gmail.com
}

\begin{abstract}
The quality of educational institutions is supported by several system elements including supervision of education carried out by principals as supervisors as mandated by Minister of National Education Regulation (Permendiknas) Number 13 of 2007 concerning Standard Principals who must supervise education in the form of supervision and assessment of teacher performance and employees who aim to assist teachers and employees in achieving educational goals starting from planning, implementation and evaluation to be optimal in carrying out institutional tasks in an organizational frame that leads to the quality of the institution. Educational supervision serves to coordinate all school efforts including all role holders in the school organization and broaden the experience through giving constructive criticism from the principal to teachers and employees. References to educational supervision include curriculum components, curriculum content and curriculum development strategies, improvement of teaching references in terms of making learning planning, optimizing the educational functions and educational goals embodied in the school's vision and mission.
\end{abstract}

Keyword: Supervision of Education, Schools.

\section{PENDAHULUAN}

Perkembangan supervisipendidikandisekolah yangsudah maju, dapat dilihat bahwa peran supervisor telah berkembang secara bertahap dengan standarisasi yang akuntable.Format penilaian yang lengkap dalam supervisi pendidikan menjadikan hal yang terkecil dalam pelaksanaan pendidikan dapat diamati.

Sebagaimana yang tercantum dalam Undang-undang No. 20 tahun 2003 tentang Sisdiknas pada pasal 66, membahas tentang pengawasan Pendidikan, ayat (1) Pemerintah, Pemerintah Daerah, dewan pendidikan, dan komite sekolah/ madrasah melakukan pengawasanatas penyelenggaraan pendidikan pada semua jenjang dan jenis Pendidikan sesuai dengan kewenanganmasing-masing. (2) Pengawasan sebagaimana dimaksud dalam ayat (1) dilakukan dengan prinsip transparansi dan akuntabilitaspublik ${ }^{1}$.

\footnotetext{
${ }^{1}$ Undang-undang No. 20 tahun 2003 tentang Sistem Pendidikan Nasional
} 


\section{Bustanul Ulum}

Gurusebagaipelaksanapendidikandan karyawan sebagai pendukung dalam sekolah perlu sekali dilakukan supervisioleh kepala sekolah sebagai tolok ukur kinerja.Kegiatan supervisi tersebut dapat dijadikan kegiatan melihat aktivitas secara langsung dilapangan, dengan harapan ada perbaikan terhadap beberapa sistem yang masih kurang relevan dan meningkatkan pada sistem yang sudah baik.Supervisi pendidikan diharapkan juga dapat berpengaruh terhadap kinerja guru dan karyawan pada satuan pendidikan, karena dalam pelaksanaan pendidikan perlu adanya peningkatan dan kemajuan, sebab pendidikan bersifat dinamis sesuai dengan jaman.

Keadaan tersebut telah dituangkan dalam al-Qur'an

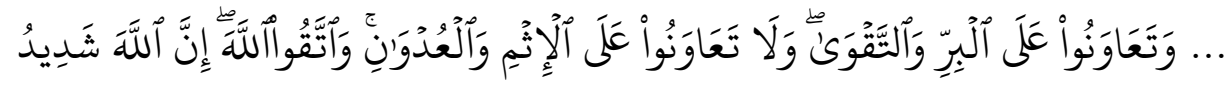

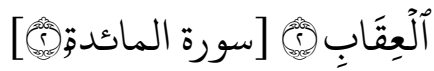

Artinya:

"... Dan tolong-menolonglah kamu dalam (mengerjakan) kebajikan dan takwa, dan jangan tolong-menolong dalam berbuat dosa dan pelanggaran.Dan bertakwalah kamu kepada Allah, sesungguhnya Allah amat berat siksa-Nya [Al Ma"idah2].

Ayat tersebut di atas menerangkan bahwa perlunya kinerja seseorang dibantu dengan yang lainnya. Pekerjaan yang dilakukan dengan kebersamaan akan membuat pekerjaan tersebut menjadi ringan dan mudah untuk dilaksanakan.

Di dalam Peraturan Menteri Pendidikan Nasional (Permendiknas) Nomor 13 Tahun 2007 tentang Standar Kepala Sekolah ditegaskan bahwa salah satu kompetensi yang harus dimiliki seorang kepala sekolah adalah kompetensi kepribadian, kompetensi menejerial, kompetensi supervisi, kompetensi sosial dan kompetensi kewirausahaan ${ }^{2}$. Dengan Permendiknas tersebut berarti seorang kepala sekolah harus kompeten dalam melakukan supervisi terhadap guru dan karyawan yang dipimpinnya, termasuk juga dalam kegiatan supervisi yang arahnya adalah perbaikan kinerja, kekurangan kinerja seseorang akan bisa dilihat oleh orang lain, inilah yang dimaksud dengan tolong-menolong dalam hal peningkatan kualitas penyelenggaraan pendidikan.

\section{PEMBAHASAN}

\section{Pengertian Supervisi pendidikan}

Supervisipendidikan diartikan sebagai serangkaian kegiatan membantu guru untuk mengembangkan kemampuannya mengelola proses pembelajaran demi

\footnotetext{
${ }^{2}$ Permendiknas Nomor 13 Tahun 2007 tentang Standar Kepala Sekolah
} 
pencapaian tujuan pembelajaran ${ }^{3}$.

Supervisi menurut Purwanto adalah segala bantuan dari pemimpin sekolah yang tertuju pada perkembangan kepemimpinan guru-guru dan personel sekolahlainnya dalam mencapai tujuan Pendidikan ${ }^{4}$

Bentuk kegiatan dalam supervisi pendidikan berupa penilaian, pengawasan, evaluasi, bimbingan dan perbaikan terhadap kinerja para guru di sekolah. Mulai bagaimana guru membuat perencanaan pelaksanaan dan sampai dengan proses guru mengevaluasi ${ }^{5}$.Jadi supervisipendidikan adalah kegiatan pimpinan sekolah dalam bentuk pengawasan dan penilaian terhadap kinerja guru yang meliputi perencanaan, pelaksanaan, penilaian dan tindak lanjut penilaian yang bertujuan untuk peningkatan kualitas kinerja guru.

\section{Tujuan Supervisi Pendidikan}

Menurut Ngalim Purwanto ${ }^{6}$ tujuan supervisipendidikan antara lain:

a. Membantu guru dengan jelas dalam mencapai tujuan-tujuan Pendidikan

b. Membantu guru dalam membimbing pengalaman belajar murid

c. Membantu guru dalam menggunakan media pembelajaran dan sumbersumber belajar

d. Membantu guru dalam menilai kemajuan murid-murid

e. Membantu guru-guru baru disekolah sehingga mereka merasa gembira dengan tugasnya

f. Membantu guru-guru agar bisa optimal dalam melaksanakan tugas kelembagaan

Tujuan supervisi menurut Syukur ${ }^{7}$ :

a. Membantu guru melihat tujuan Pendidikan

b. Membantu guru dalam membimbing pengalaman pembelajaran

c. Membantu guru dalam penggunaan sumber belajar

\footnotetext{
${ }^{3}$ Fatah Syukur, Manajemen Pendidikan Berbasis pada Madrasah (Semarang: Pustaka Riski Putra, 2013), 96.

${ }^{4}$ Ngalim Purwanto, Administrasi dan Supervisi Pendidikan (Bandung: Remaja Rosdakarya 2012),76

${ }^{5}$ Lihat Gery, Devis, A., Effective Schools and Affective Teachers (Madison: University of Wisconsin, 1994), 172-177. Lihat juga Herabuddin, Administrasi dan Supervisi Pendidikan (Bandung: Pustaka Setia,200),195.

${ }^{6}$ Purwanto, Ngalim, Administrasi dan Supervisi Pendidikan(Bandung: RemajaRosdakarya, 2012), 25

${ }^{7}$ Fatah Syukur, Manajemen Pendidikan Berbasis pada Madrasah (Semarang: Pustaka Riski Putra, 2013), 101.
}

FalAsIfa, Vol. 9 Nomor 2 September 2018 | 129 


\section{Bustanul Ulum}

d. Membantu guru dalam menggunakan metode pembelajaran

e. Membantu dalam hal penilaian

f. Pembinaan profesionalisme guru

g. Membantu guru dalam pembagan waktu

MenurutMulyasatujuan supervisi antara lain:

a. Mengembangkan iklim pembelajaran yang kondusif

b. Membantu guru dalam membimbing belajar siswa ${ }^{8}$

c. Membantu guru dalam menggunakan media pembelajaran dan metodemetode pembelajaran'.

Berdasarkan pemaparan di atas,maka supervisi pendidikan bertujuan untuk membantu guru dalam mencapai tujuan-tujuan pendidikanmulai dari perencanaan, pelaksanaan dan evaluasi.Membantu guru dalam menggunakan media pembelajaran dan sumber-sumber belajar lainnya.Membantu guru dalam menilai kemajuan murid-murid pada setiap tingkatannya pada bidang kognitif, afektif dan psikomotorik.Membantu guru-guru agar bisa optimal dalam melaksanakan tugas kelembagaan dalam bingkai keorganisasian yang mengarah kepada mutu lembaga.

\section{Fungsi Supervisi Pendidikan}

Fungsi supervisi menurut E. Mulyasa sebagai berikut:

a. Mengkoordinir semua usaha sekolah

b. Memperluas pengalaman guru

c. Menstimulir usaha-usaha yang kreatif

d. Memberikan fasilitas dan penilian yang terus menerus

e. Menganalisa situasi pembelajaran

f. Memberikan pengatahuan dan skill kepada bawahan ${ }^{10}$.

Supervisi pendidikan yang efektif secara operasional oleh Jerry dan Makawimbang memiliki 9 fungsi ${ }^{11}$ :

a. Disiplin

Pelaksanaan supervisipendidikan dikatakan disiplin apabila pelaksanaan supervisi sesuai dengan perencanaan yang telah ditetapkan dalam program kerja kepala sekolah secara berkesinambungan.

${ }^{8}$ A. Gery, Devis, Effective Schools and Affective Theachers, (Madison: University of Wisconsin, 1994), 170. 157

${ }^{9}$ E. Mulyasa, Manajemen Berbasis Sekolah (Bandung:Remaja Rosdakarya, 2009),

${ }^{10}$ E. Mulyasa, ...158

${ }^{11}$ St. Rodliyah, Supervisi Pendidikan dan Pembelajaran (Jember: STAIN Jember Press, 2014), 12.

130 | FaLASIFA, Vol. 9 Nomor 2 September 2018 
b. Memberi rasa aman kepada guru

Dalam hal ini pelaksanaan supervisi pendidikan yang dilakukan oleh kepala sekolah merupakan kegiatan yang bersifat kostruktif dan bernuansa kekeluargaan.

c. Konstruktif

Pelaksanaan supervisi pendidikan yang dilakukan oleh kepala sekolah diharapkan mampu memberi sumbangsih pemikiran dan konsep untuk mengarahkan guru kepada peningkatan konpetensinya.

d. Kreatif

Indikator kreatif yang dimaksud disini adalah kompetensi yang harus dimiliki oleh kepala sekolah untuk mengemas aktivitas supervisi dengan beberapa konsep baru yang kreatif.

e. Realistis

Artinya pelaksanaan supervisi pendidikan yang dilakukan oleh kepala sekolah menilai sesuai dengan fakta dan menyampaikan kepada guru yang bersangkutan juga sesuai dengan fakta.Seluruh kelebihan dan kekurangan guru disampaikan sesuai dengan fakta yang ditemukan.

f. Sederhana

Sederhana disini adalah kegiatan supervisi pendidiakan dilaksanakan dengan tidak menuntut banyak kepada guru yang akan disupervisi. Guru diharapkan natural saja sebagaimana proses pembelajaran yang biasanya dilakukan.

g. Hubungan profesional

Hubungan professional artinya adalah kepala sekolah dalam melaksanakan supervisi pendidikan menggunakan pedoman standar penilaian supervisi yangbaku dari pemerintah. Mulai dari perencanaan, pelaksanaan dan evaluasi pembelajaran yang dilakukan oleh guru.

h. Proporsional

Proporsional dalam supervisi pendidikan berarti pelaksanaan supervisi pendidikan dilakukan atas dasar ketentuan yang telah ada.

i. Kemandirian

Sedangkan menurut Mukhtar Iskandar, menjelaskan fungsi supervisi pengajaran, antara lain:

a. Mengkoordinasi semua usaha sekolah

b. Melengkapi kepemimpinan sekolah

c. Memperluas pengalaman

d. Menstimulasi usaha-usaha yang kreatif

e. Memberikan penilaian yang terus-menerus

f. Menganalisis situasi belajar

FALASIFA, Vol. 9 Nomor 2 September 2018 | 131 


\section{Bustanul Ulum}

g. Memberi pengatahuan dan keterampilan

h. Mengintegrasikan tujuan ${ }^{12}$.

Berdasarkan beberapa pendapat di atas, maka fungsi supervisi pendidikanadalah untuk mengkoordinasi semua usaha sekolah meliputi seluruh pemegang peranan dalam organisasi sekolah.Memperluas pengalaman melalui saling memberi kritik yang konstruktif dari kepala sekolah kepada para guru.Mengetahui sejauh mana pelaksanaan pendidikan yang dilakukan oleh guru kerena supervisi dilakukan secara langsung turun kedalam kelas, Menstimulasi usaha-usaha yang kreatif dari guru-guru atas informasi yang diberikan oleh kepala sekolah.Menganalisis situasi belajar dari setiap guru, karena supervisi pendidikan bersifat universal kepada semua tenaga pendidik.Mengintegrasikan tujuan sekolah melalui tim tenaga pendidik.

1. Lingkup Supervisi Pendidikan

Menurut pedoman kepengawasan Dirjen Pendais ${ }^{13}$, lingkup pelaksanaan supervisi pendidikan meliputi:

a. Perencanaan guru yang dimulai dari penyususnan program pengajaran, menyajikan program pengajaran, evaluasi belajar, dan sampai pada tindak launjut.

b. Pelaksanaan pembelajaran yang meliputi alur pembelajaran, kesesuaian konsep materi pembelajaran, penyesuaian pelaksanaan dengan perencanaan guru, penyesuaian penggunaan alat dan media pembelajaran, dan pemanfaatan alokasi waktu.

c. Penilaian yang meliputi kesesuaian metode penilaian dengan materi, ketepatan dalam pembuatan soal, ketepatan dalam memberi penilaian terhadap masingmasing soal.

d. Analisis hasil penilaian

e. Tindak lanjut hasil penilaian

Dari pemaparan di atas lingkup pelaksanaan supervisi pendidikan yang dilakukan oleh kepala sekolah terhadap guru meliputi seluruh aktifitas guru mulai dari perencanaan pembelajaran, pelaksanaan pembelajaransampai dengan evaluasi pembelajaran yang masing-masing pada segmentasinnya memiliki beberapa sub kajian dan aktivitas tersendiri.

Termasuk juga analisis hasil penilaian dan tindak lanjutberikutnya.Berupa analisis butir soal yang dipadukan dengan hasil kinerja siswa kemudian mengolahnya sehingga menghasilkan sebuah kesimpulan. Dari kesimpulan tersebur akan dilaksanakan tindak lanjut dalam bentuk remidi atau penambahan jam mengajar.

\footnotetext{
${ }^{12}$ Fatah Syukur, Manajemen Pendidikan Berbasis pada Madrasah (Semarang: Pustaka Riski Putra, 2013), 102-104.

${ }^{13}$ Dirjen Pendais,Pedoman Kepengawasan, 2007.56.
} 
2. Acuan Supervisi Pendidikan

Acuan supervisiPendidikan menurut pedoman kepegawasan Dirjen Pendais antara lain ${ }^{14}$ :

a. Peningkatan kurikulum

b. Acuan pengajaran

c. Pengertian Pendidikan

d. Fungsi Pendidikan

e. Tujuan Pendidikan

f. Ruang lingkup Pendidikan

g. Pendekatan pembelajaran

h. Kemampuan siswas

i. Alokasi waktu

j. Pola pembinaan Pendidikan terpadu

Dari keterangan di atas, maka acuan supervisi pendidikan meliputi Peningkatan kurikulum meliputi komponen kurikulum, isi kurikulum dan strategi pengembangan kurikulum.Peningkatan acuan pengajaran dalam hal pembuatan perencanaan pembelajaran.Optimalisasi Fungsi pendidikan dan tujuan pendidikanyang termaktub dalam visi dan misi sekolah.Pendekatan pembelajaran yang sesuai dengan kebutuhan dan perkembangan zaman.Mengklasifikasikan kemampuan siswadalam rangka pemetaan kebutuhan siswa.

\section{Kepala Sekolah Sebagai Supervisor}

Di dalam Peraturan Menteri Pendidikan Nasional (Permendiknas) Nomor 13 Tahun 2007 tentang Standar Kepala Sekolah ditegaskan bahwa salah satu kompetensi yang harus dimiliki seorang kepala sekolah adalah kompetensi kepribadian, kompetensi menejerial, kompetensi supervisi, kompetensi sosial dan kompetensi kewirausahaan ${ }^{15}$. Dengan Permendiknas tersebut berarti seorang kepala sekolah harus kompeten dalam melakukan supervisi terhadap guru-guru yang dipimpinnya, termasuk juga dalam kegiatan supervisi yang arahnya adalah perbaikan kinerja, kekurangan kinerja seseorang akan bisa dilihat oleh orang lain.

Kepala sekolah sebagai supervisor memiliki peran yang strategis dalam meningkatkan mutu lembaga pendidikan. Dalam menjalankan fungsinya sebagai supervisor kepala sekolah harus menguasai tugas-tugasnya dan melaksanakan tugasnya dengan baik, ia bertanggung jawab terhadap seluruh kegiatan sekolah, mengatur proses belajar mengajar, mengatur hal-hal yang menyangkut kesiswaan, personalia, sarana dan prasarana yang dibutuhkan dalam proses pembelajaran, ketatausahaan, keuangan serta mengatur hubungan dengan masyarakat.

\footnotetext{
${ }^{14}$ Dirjen Pendais,Pedoman Kepengawasan, 2007.57.

${ }^{15}$ Permendiknas Nomor 13 Tahun 2007 tentang Standar Kepala Sekolah
}

Falasifa, Vol. 9 Nomor 2 September 2018 | 133 


\section{Bustanul Ulum}

\section{KESIMPULAN}

Supervisi pendidikan adalah kegiatan pimpinan sekolah dalam bentuk pengawasan dan penilaian terhadap kinerja guru dan karyawan yang meliputi perencanaan, pelaksanaan, penilaian dan tindak lanjut penilaian yang bertujuan untuk membantu guru dan karyawan dalam mencapai tujuan-tujuan pendidikan mulai dari perencanaan, pelaksanaan dan evaluasi. Membantu guru dalam menggunakan media pembelajaran dan sumber-sumber belajar lainnya.Membantu guru dalam menilai kemajuan murid-murid pada setiap tingkatannya pada bidang kognitif, afektif dan psikomotorik.Membantu guru dan karyawan agar bisa optimal dalam melaksanakan tugas kelembagaan dalam bingkai keorganisasian yang mengarah kepada mutu lembaga.Supervisi berfungsi supervisi pendidikan adalah untuk mengkoordinasi semua usaha sekolah meliputi seluruh pemegang peranan dalam organisasi sekolah.Memperluas pengalaman melalui saling memberi kritik yang konstruktif dari kepala sekolah kepada para guru.

Lingkup pelaksanaan supervisi pendidikan yang dilakukan oleh kepala sekolah terhadap guru dan karyawan meliputi seluruh aktifitas guru dsn karyawan mulai dari perencanaan pembelajaran, pelaksanaan pembelajaran sampai dengan evaluasi pembelajaran.Acuan supervisi pendidikan meliputi Peningkatan kurikulum meliputi komponen kurikulum, isi kurikulum dan strategi pengembangan kurikulum, peningkatan acuan pengajaran dalam hal pembuatan perencanaan pembelajaran, optimalisasi fungsi pendidikan dan tujuan pendidikan yang termaktub dalam visi dan misi sekolah, pendekatan pembelajaran yang sesuai dengan kebutuhan dan perkembangan zaman dan engklasifikasikan kemampuan siswa dalam rangka pemetaan kebutuhan siswa.

\section{DAFTAR PUSTAKA}

A. Gery, Devis, 1994, Effective Schools and Affective Theachers, Madison: University of Wisconsin.

Herabuddin, 2009, Administrasi dan Supervisi Pendidika, Bandung: Pustaka Setia. Mulyasa E.,2009,Manajemen Berbasis Sekolah, Bandung: Remaja Rosdakarya.

Purwanto, Ngalim, 2012, Administrasi dan Supervisi Pendidikan. Bandung: Remaja Rosdakarya.

Rodliyah, St., 2014, Supervisi Pendidikan dan Pembelajaran, Jember: STAIN Jember Press.

Sekretariat Negara RI. Permendiknas Nomor 13 Tahun 2007 tentang Standar Kepala Sekolah kan Nasional

.Undang-undang No. 20 tahun 2003 tentang Sistem Pendidi-

Syukur, Fatah, 2013, Manajemen Pendidikan Berbasis pada Madrasah, Semarang: Pustaka Riski Putra.

134 | Falasifa, Vol. 9 Nomor 2 September 2018 